\title{
SciForum INFLUENCE OF CARBON NANOTUBES MOL2NET IN NANO-CARBOAPATITE
}

\author{
W. Knupp ${ }^{1,2 *}$, I. Camps $^{1}$, M. Mir ${ }^{2}$ \\ 1 Laboratory of Computational Modeling - LaModel, Institute of Exact Sciences - ICEx. Federal \\ University of Alfenas - UNIFAL-MG, Alfenas, Minas Gerais, Brazil, \\ E-Mail: icamps@unifal-mg.edu.br \\ 2 Laboratory of Nanobiomaterials, Institute of Exact Sciences - ICEx. Federal University of Alfenas - \\ UNIFAL-MG, Alfenas, Minas Gerais, Brazil, \\ E-Mails: mmir@unifal-mg.edu.br \\ * E-Mail: wandersogk@gmail.com; \\ Tel.: +55(35)9 9211-8356.
}

\begin{abstract}
:
One of the characteristics to be achieved by biomaterials is to have similarity to the host material. Nano carboapatite (HAC) has both considerable composition and order of magnitude in relation to human bone. For the application in cases of bone substitution, HAC would be a good candidate, but it is shown with low mechanical resistance, which would make it difficult to apply it in areas that perform high mechanical stress. However, carbon nanotubes (CNTs) have low density and strong covalent bonding between their atoms, which confers high mechanical resistance to the material. For this reason, the influence of CNTs on the structure and properties of HAC was studied. Pure CNTs (pristines) and functionalized with CNT-COOH carboxyl were inserted for the study. The results of Elemental Analysis (CHN-O) indicated the amount of carbon present in the samples in each case. The results of XRD, TG / DTA and IR showed that pristine CNTs apparently did not significantly influence the structure of HAC. However, XRD results suggested that CNTs functionalized with $\mathrm{COOH}$ clusters may have interacted with HAC. In this case, the displacement of some peaks was observed in the sample (HAC + CNT_COOH), showing a decrease in the c axis of the sample. The refinement of the diffractograms also revealed samples of the nanometric order, with crystallite size in the order $25 \AA$. The results of the thermal analysis showed a peak close to $600{ }^{\circ} \mathrm{C}$, associated to the decomposition of the carbonate; Indicating the presence of these ions in the A site of HAC. The IR spectra showed the vibrational modes corresponding to the carbonate ion, confirming the presence of these ions in sites $A$ and $B$.
\end{abstract}

Keywords: Nano carboapatite, Carbon nanotubes.

Introduction: Apatite is a mineral having the general formula $\left[\mathrm{A}(1)_{2}\right]\left[\mathrm{A}(2)_{3}\right]\left[\left(\mathrm{BO}_{4}\right)_{3} \mathrm{X}\right]$, formed by several types of ions. $\mathrm{A} B$ and $\mathrm{X}$ represent the possible sites where we can substitute different ions, changing the properties of the compound [1]. Among a family of apatites most studied such as fluorapatite, chlorapatites and hydroxyapatites, the latter can be described in the formula $\left[\mathrm{Ca}_{10}\left(\mathrm{PO}_{4}\right)_{6}(\mathrm{OH})_{2}\right]$ being able to act as a perfect bone substitute, since approximately $75 \%$ of the mineral part of the bone tissue and constitute of this material. In general, the hydroxyapatite allows all of its ions to be replaced and can occupy the hydroxyl sites $\mathrm{OH}^{-}$called site $\mathrm{A}$, and phosphate $\mathrm{PO}_{4}^{3-}$ called site $\mathrm{B}$. The incorporation of the carbonate ion $\mathrm{CO}_{3}^{2-}$ may occur on the site $\mathrm{A}, \mathrm{B}$ or both, originating nano carboapatite (HAC) [2]. However, high carbonate substitution at the site $B$, leads to a decrease in the crystallinity of the sample, thus increasing its resemblance to human bone.

Another material that draws much attention is carbon nanotubes (CNTs), discovered by Iijima in 1991, they present several properties of interest 
such as large surface area, nanocapillary, and environmentally susceptible electronic properties that are exposed [3]. Even with all these properties, there is a discussion about the low reactivity of CNTs, due to its high chemical stability. However many of the applications take into account a previous treatment, making oxidation that promotes a better dispersion or introducing hydrophilic groups like hydroxyl ($\mathrm{OH})$ or carboxyl $(-\mathrm{COOH})$ which leads to the functionalization of the material, so we have a probable increase in the reactivity of the CNTs [4].

Materials and Methods: Nano Carboapatite (HAC) and nano (HA) were synthesized by aqueous precipitation of the solutions of $\left(\mathrm{NH}_{4}\right)_{2} \mathrm{HPO}_{4},\left(\mathrm{NH}_{4}\right)_{2} \mathrm{CO}_{3}$ and $\mathrm{Ca}\left(\mathrm{NO}_{3}\right)_{2} \quad 4 \mathrm{H}_{2} \mathrm{O}$, with the molarities required to obtain $6 \%$ carbonate in the HAC sample according to the conditions detailed in patent [5].

To obtain the samples of HACCNT and HACCNTCOOH, in the synthesis was introduced $1 \%$ in CNTs pristine (to HACCNT) and functionalized with carboxyl (to HACCNTCOOH) respect to the total mass of HAC. The solution was kept under constant stirring, with controlled temperature and $\mathrm{pH}$ regulated by the solution of $\mathrm{KOH}$. Final homogenization was done on ultrasound for 10 minutes. The sample was washed, filtered vacuum and dried for 24 hours.

The samples were characterized by X-ray diffraction (DRX) (2theta: 10-90 degrees, step: 0,02), infrared spectrometry (IV) (400- $4000 \mathrm{~cm}^{-1}$ ), thermal analysis (TG-DTA) (30-1100) ${ }^{\circ} \mathrm{C}$, the flow of $\mathrm{N}_{2}: 50 \mathrm{ml} / \mathrm{min}$ ) and by Elemental Analysis (CHNS-O). The microstructure was obtained from the refinement of the diffractograms using software Fullprof [6], by the spherical harmonics method.

Results and Discussion: (CHNS-O)- The results of the carbon contents obtained by elemental analysis are presented in Table 1 together with the carbonate contents, (column \% $\mathrm{CO}_{3}$ ), in this table the column \%C the values of the percentage of carbon obtained from the equipment for each sample appear. The carbonate levels determined by this analysis were relatively close to those obtained by the analyzes of the TG curves of the samples, suggesting good consistency between the analysis and characterization methods used.

The higher percentages for the HACCNT and HACCNTCOOH samples are related to the fact that for these samples we have a higher amount of carbon, due to the introduction of the CNTs.

Table 1- Experimentally determined carbon and carbonate contents.

\begin{tabular}{l|cc}
\multicolumn{1}{c}{ Samples } & $\%^{\dagger}$ & $\% \mathrm{CO}_{3}{ }^{\dagger \dagger}$ \\
\hline HA & 0,0000 & 0,0000 \\
HAC & 1,1617 & 5,8046 \\
HACCNT & 1,9338 & - \\
HACCNTCOOH & 2,5368 & - \\
† \%m attributed to carbon content. \\
†' Determined from the carbon content. \\
${ }^{*}$ The value of sample HA was discounted because it did not \\
contain carbonate.
\end{tabular}

(DRX)- In figure 1, we can observe of the width at half height of the peaks that the sample HA was the one that presented greater crystallinity. The refinement result showed a crystal size about

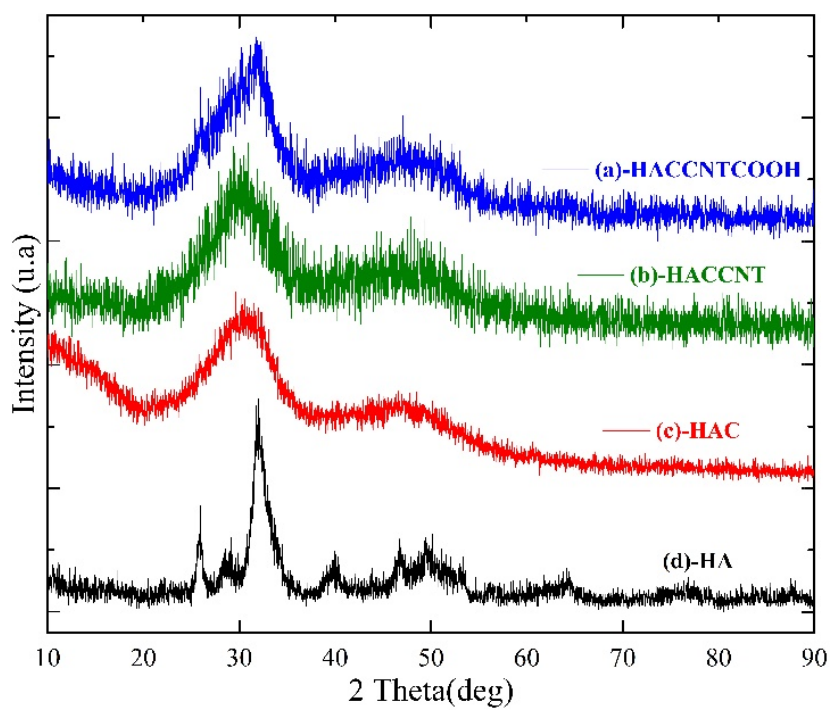

Figure 1 - Diffraction patterns of synthesized samples.

$40,61 \AA$ for this sample. The refinements results were indicated in Table 2, in this case all the samples presented structures of the nanometric order.

The HAC and HACCNT samples showed no significant change indicating that the introduction of CNT pristine modified the structure of the compound as expected, coupled with the low reactivity of the pure CNTs.

In the HACCNTCOOH sample, we can observe a slight shift from the peak of higher intensity to higher values in $2 \theta$, indicating changes in cell 
Table 1- ${ }^{\dagger}$ Apparent mean crystallite size, ${ }^{\dagger \dagger}$ Mean anisotropic $\quad$ standard deviation, Strain, volume and cell parameters.

\begin{tabular}{l|ccccc}
\multicolumn{1}{c|}{ Samples } & T.C. $^{\dagger}(\text { Aniso. })^{\dagger \dagger}(\AA)$ & Strain (Aniso. $)^{\dagger \dagger}(\AA)$ & $\mathrm{V}\left(\AA^{3}\right)$ & $a(\AA)$ & $c(\AA)$ \\
HA & $40,61(18,98)$ & - & $524,2(2)$ & $9,381(2)$ & $6,879(1)$ \\
HAC & $21,77(1,85)$ & $201,0781(0,2165)$ & $533,5(9)$ & $9,283(5)$ & $7,15(1)$ \\
HACCNT & $27,66(4,73)$ & $197,2456(0,4285)$ & $545(1)$ & $9,30(1)$ & $7,28(1)$ \\
HACCNTCOOH & $17,79(4,91)$ & $241,7641(0,3307)$ & $522(1)$ & $9,378(7)$ & $6,85(1)$
\end{tabular}

parameters. This can be attributed to the fact that CNT functionalized with carboxyl have greater interaction with HAC.

The refinement revealed samples with little crystallinity, proving the nanometric order, with crystallite size around $25 \AA$, the sample HACCNTCOOH had its volume slightly reduced compared to the sample HACCNT, while its axis $c$ (preferential axis of crystal growth) also shows this reduction (see table 2). This change in the $c$ again points out that carboxyl-functionalized CNTs have a better interaction with HAC compared to pristine CNTs.

(IV)- Figure 2 (a) (b) illustrates the IR spectra obtained for HA with $0 \%$ of carbonate and HAC with $6 \%$ of carbonate inserted into its structure. In the graph, the sample HA, indicated in curve (a), presents a band near $3500 \mathrm{~cm}^{-1}$ and another around (1635-1645) $\mathrm{cm}^{-1}$ corresponding to the vibration modes of the grouping $\mathrm{OH}^{-}$. The bands around $1050 \mathrm{~cm}^{-1}, 964 \mathrm{~cm}^{-1}, 952 \mathrm{~cm}^{-1}$ corresponding to the asymmetric stretching modes of phosphate and $602 \mathrm{~cm}^{-1}, 569 \mathrm{~cm}^{-1}$, a deformação assimétrica do $\mathrm{PO}_{4}{ }^{3-}$. For this same spectrum, bands related to carbonate. This may be justified by the fact that hydroxyapatite is highly hygroscopic, and by the amount of $\mathrm{CO}_{2}$ present in the environment, increasing the amount of carbonate on the surface of the material.

This idea is reinforced by the fact that in TG- DTA and elemental analysis we can prove that this sample does not have carbon in its structure $[7,8]$.

For the sample HAC, indicated in curve (b), the vibrational modes of the carbonate ion are observed in $1490 \mathrm{~cm}^{-1}$ for substitution at site A, is at $1430 \mathrm{~cm}^{-1}$ and $870 \mathrm{~cm}^{-1}$ for substitution at site $\mathrm{B}$. The higher intensity of these bands in the HAC sample compared to the HA indicates the substitution of the carbonate ion at site $\mathrm{A}$ and $\mathrm{B}$
[9-12]. In the curve (c) CNT, no oxidative process was performed on the surface of the CNTs to perform the measurements, and even then we could observe some bands characteristics of the CNTs. In the curve (d) CNTCOOH, we observed the band in $1546 \mathrm{~cm}^{-1}$ attributed to the molecular group $\mathrm{C}-\mathrm{C}$ and the

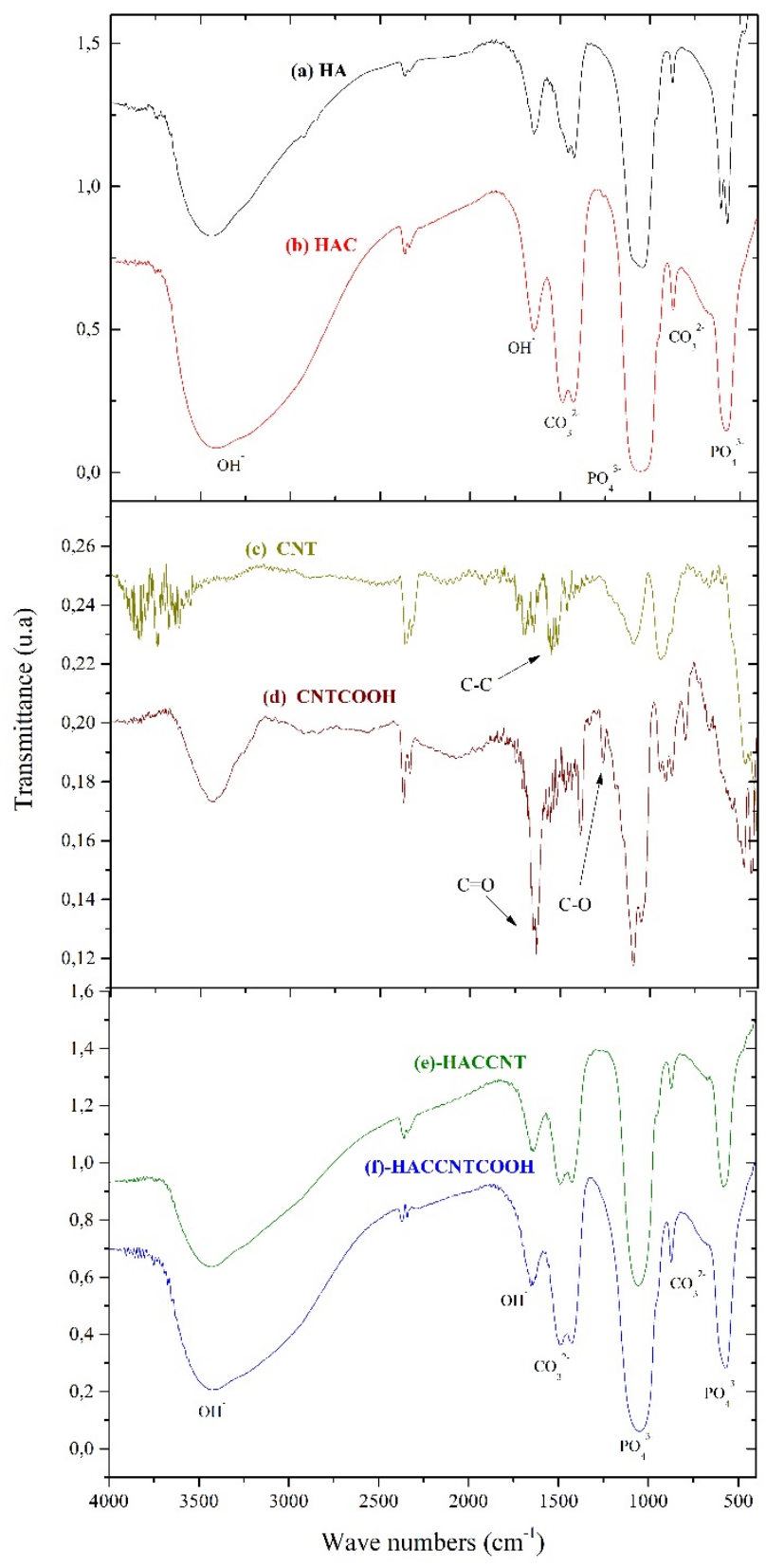

Figure 2 - IR spectra for the samples obtained. 
peak observed in $1625 \mathrm{~cm}^{-1}$ was attributed to stretching $\mathrm{C}=\mathrm{O}$ of the carboxyl group $(\mathrm{COOH})$. Already the band obtained in $1261 \mathrm{~cm}^{-1}$ was related to the elongation of $\mathrm{C}-\mathrm{O}$ [13]. For the samples HACCNT curve (e) and HACCNTCOOH curve (f) we can observe the characteristic modes of HAC where we can see in $1490 \mathrm{~cm}^{-1}, 1430 \mathrm{~cm}^{-1}$ and $870 \mathrm{~cm}^{-1}$ the vibrational modes of the ion $\mathrm{CO}_{3}{ }^{2-}$ indicating the replacement of the type AB. However, the vibrational modes corresponding to the CNTs and the carboxyl were not observed, this may be due to the low concentration of CNTs in the samples corresponding to $1 \%$ in relation to the total mass of the samples produced.

(TG-DTA)- Figure 3 shows all DTA results obtained from the samples. With the carbonate insertion into the crystalline structure of the sample, it becomes thermally less stable. In this case, a peak appears near $600{ }^{\circ} \mathrm{C}$ which we associate with the degradation of carbonate in $\mathrm{CO}_{2}$. These peaks suggest $\mathrm{OH}$ fur $\mathrm{CO}_{3}{ }^{2-}$ an at site A of the structure. In sample HA no carbonate was inserted into the structure and this peak was not identified.

In the HACCNTCOOH sample, the peak appears shifted to lower temperatures as can be seen in figure 3 . This suggests that the exit temperature of the carbonate in the structure was influenced by the interaction between the functionalized CNTs and the HAC.

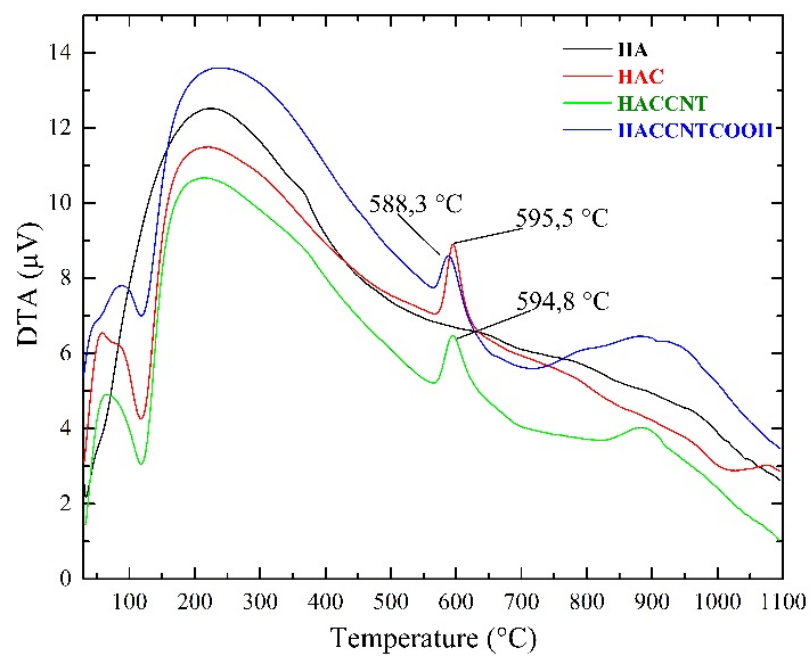

Figure 3. DTA curves for all samples.

The profile of the TG and DTA curves obtained in an air atmosphere for the CNTs are shown in
Figure 4. In the figure, it can be observed that the oxidation temperature for the nanotubes is approximately $600^{\circ} \mathrm{C}$ Slight mass losses below $500^{\circ} \mathrm{C}$ can be attributed to the removal of amorphous carbon in samples [14]. It is also possible to observe a sudden loss of mass between $540-670{ }^{\circ} \mathrm{C}$, which was attributed to the total burning of CNTs [15].

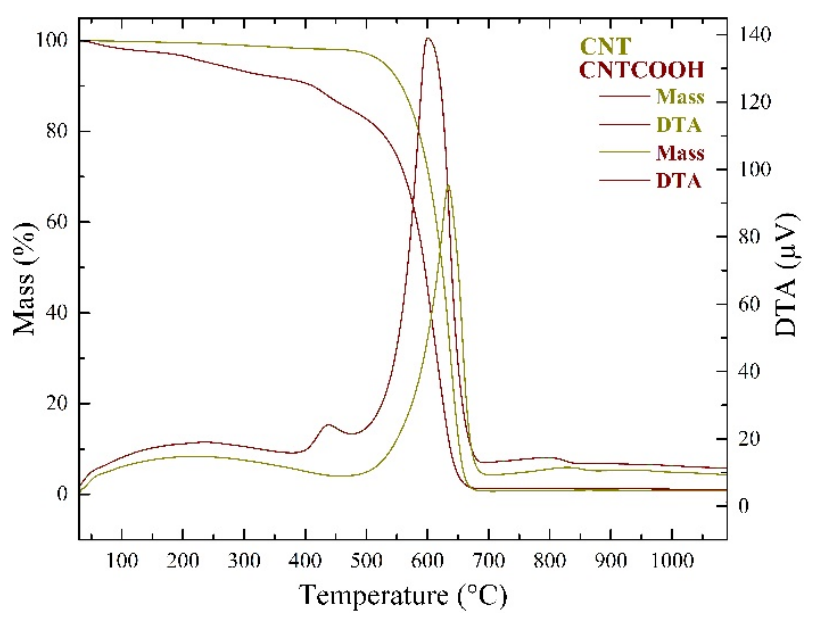

Figure 4- TG / DTA curves for carbon nanotubes.

The percentage of - $\mathrm{COOH}$ introduced into the CNT was estimated from the DTA results. This was suggested by the exothermic peak observed between 400-500 ${ }^{\circ} \mathrm{C}$ for the $\mathrm{CNTCOOH}$ sample, which was not observed for pristine CNTs. For this reason, it is suggested that the entire carboxyl was degraded to $500^{\circ} \mathrm{C}$. This mass loss, approximately $6,7 \%$ of the total mass, can be associated to the functionalization of CNTs.

Conclusões: The introduction of the carbonate ion in the samples revealed a significant change in the size of the crystallite. In all samples with HAC, the average crystallite size obtained from the XRD was of the order of $\sim 25 \AA$. The IR spectra allowed to identify the vibrational modes of the HAC, but the vibrational modes of the CNTs were not observed. This may be associated with the low concentration of CNTs inserted in the samples. The results of DTA confirmed that the carbonate in the HAC structure makes them thermally less stable, evidenced by the appearance of the peak near $600^{\circ} \mathrm{C}$. The shift from this peak to lower temperatures for the HACCNTCOOH indicates that the CNTCOOH interact with the HAC 
facilitating the carbonate output of the structure. In this work it was observed that the CNTs functionalized with - $\mathrm{COOH}$ interact better with nano-carboapatite than the non-functionalized (pristine CNTs).

\section{References:}

1. WHITE, T. J.; ZHILI, D. Structural derivation and crystal chemistry of apatites. Acta Crystallogr, 2003, 59, 1-16.

2. MAVROPOULOS, E. et al. Studies on the mechanisms of lead immobilization by hydroxyapatite. Environ. Sci. Technol, 2002, 36, 1625-1629.

3. IIJIMA, S. Helical microtubules of graphitic carbon. Nature, 1991, 353, 56-58.

4. BALASUBRAMANIAN, K.; BURGHARD, M. Chemically functionalized carbon nanotubes. Nano Micro Small,2005, 1, 180-192.

5. UNIFAL-MG e FAPEMIG, M. Mir.; R.S Geonmonond. et al. Carboapatita Nanométrica Com Especificidade Para Regeneração Óssea. 2015. BR 102015011732 9; WO 2016/18765 A1.

6. Rodriguez-Cavajal, J. Guide to Program FULLPROF for Rietveld Analysis of X-Ray and Neutron Powder Diffraction Patterns with a 'PC' and various other computers. [S.l.], 2001.

7. ZHAO, J. et al. Improving mechanical and biological properties of macroporous HA scaffolds through composite coatings. Colloids Surf., B 2009, 74, 159-166.

8. BEZZI, G. et al. A novel sol-gel technique for hydroxyapatite preparation. Mater. Chem. Phys 2003, 78, 816-824.

9. IVANOVA, T. I. et al. Crystal structure of calcium-deficient carbonated hydroxyapatite. Thermal decomposition. J. Solid State Chem 2001, 160, 340-349.

10. GIBSON, I. R.; BONFIELD, W. Novel synthesis, and characterization of an ab-type carbonatesubstituted hydroxyapatite. J. Biomed. Mater. Res 2002, 59, 697-708.

11. KRAJEWSKI, A. et al. Synthesis of carbonated hydroxyapatites: efficiency of the substitution and critical evaluation of analytical methods. J. Mol. Struct 2005, 221-228.

12. FATHI, M.; HANIFI, A.; MORTAZAVI, V. Preparation and bioactivity evaluation of bone-like hydroxyapatite nanopowder. J. Mater. Process. Technol 2007, 2, 536-542.

13. MENDES, R. M. et al. Effects of single wall carbon nanotubes and its functionalization with sodium hyaluronate on bone repair. Life Sciences 2010, 87, 215-222.

14. LI, Z. et al. Synthesis of high-quality single-walled carbon nanotubes by high-frequency induction heating. Physica E, 2008, 40, 452-456.

15. YANG, K. et al. The effect of chemical treatment on the crystallinity of multi-walled carbon nanotubes. J. Phys. Chem. Solids, 2008, 69, 222-229. 